This is the author version of the following article: Baltimore, Joseph A. (2013). "Type Physicalism and Causal Exclusion." Journal of Philosophical Research, 38, 405-418. The final publication is available at: http://dx.doi.org/10.5840/jpr20133821

\title{
TYPE PHYSICALISM AND CAUSAL EXCLUSION
}

\section{INTRODUCTION}

According to Jaegwon Kim's (1998; 2005) “supervenience argument," non-reductive physicalism is incompatible with mental causation. Kim claims that non-reductive physicalism is committed to the following two theses:

Mind-body supervenience: Mental properties supervene on physical properties, in that necessarily, for any mental property, $M$, if anything has $M$ at time $t$, there exists a physical base (or subvenient) property, $\mathrm{P}$, such that it has $\mathrm{P}$ at $\mathrm{t}$, and necessarily anything that has $\mathrm{P}$ at a time has $\mathrm{M}$ at that time.

Mental/physical property dualism: Mental properties are not reducible to, and are not identical with, physical properties.

Kim also adopts the following principle:

Causal exclusion principle: No single event can have more than one sufficient cause occurring at any given time (unless it is a genuine case of causal overdetermination).

The problem for mental causation then unfolds thusly:

(1) Assume that an instantiation of a mental property, M, causes an instantiation of another mental property, $\mathrm{M}^{*}{ }^{2}$

(2) By mind-body supervenience, $\mathrm{M}^{*}$ has a physical supervenience base, $\mathrm{P} *$.

(3) If $\mathrm{M}$ causes $\mathrm{M}^{*}$ and $\mathrm{M}^{*}$ has physical supervenience base $\mathrm{P}^{*}$, then $\mathrm{M}$ causes $\mathrm{M}^{*}$ by causing $\mathrm{P}^{*}$.

\footnotetext{
${ }^{1}$ This version of supervenience is known as "strong supervenience" (Kim 1998: 9; 2005: 33). In the context of the supervenience argument, $\operatorname{Kim}(2005: 33 \mathrm{fn}$. 2) appears to prefer remaining as neutral as possible on how, exactly, to understand the occurrences of "necessarily." Yet Kim (1998: 39) also appears to assume that the necessities will at least be nomological necessities. Following Kim, let us take both necessities to hold with at least nomological force, leaving open whether either of them have the stronger modal force of a logical or metaphysical necessity.

${ }^{2}$ Kim takes instantiations of properties, or property instances, to enter into causal relations. I will often sacrifice, for the sake of simplicity, explicit identification of property instances as such.
} 
(4) Hence, M causes P*.

(5) By mind-body supervenience, $\mathrm{M}$ has a physical supervenience base, $\mathrm{P}$.

(6) If $\mathrm{M}$ causes $\mathrm{P}^{*}$ and $\mathrm{M}$ has physical supervenience base $\mathrm{P}$, then $\mathrm{P}$ causes $\mathrm{P}^{*}$.

(7) Hence, $P$ causes $P^{*}$.

(8) By mental/physical property dualism, $\mathrm{M}$ is distinct from $\mathrm{P}$.

(9) Hence, $\mathrm{P}^{*}$ has two distinct causes, $\mathrm{M}$ and $\mathrm{P}$.

(10) But, by the causal exclusion principle (and the assumption that $\mathrm{P} *$ is not causally overdetermined), this result is unacceptable.

As Kim indicates, there are two stages to this argument. The first stage is advanced through premises (1)-(4) and argues that mental-to-mental causation requires mental-to-physical causation. The second stage, (4)-(10), argues that the required mental-to-physical causation is problematic. From these two stages, Kim concludes that non-reductive physicalism cannot accommodate either sort of mental causation.

Non-reductive physicalists have wrestled extensively with Kim's argument. Yet it is standardly assumed that reductive type physicalism is immune to the exclusion problem, since type physicalists deny mental/physical property dualism. Type physicalists may identify $\mathrm{M}$ with $\mathrm{P}$, which would clearly allow for "both" of them to cause $\mathrm{P} *$ without running afoul of the causal exclusion principle. Call this type physicalism's “identity advantage."

In the present paper, I challenge this widely accepted advantage of type physicalism over non-reductive physicalism in avoiding the causal exclusion of the mental. First, I defend the point that the supervenience argument generalizes so as to call into question the causal efficacy of all higher-level properties. Second, I make clear that the type physicalist qua physicalist cannot countenance mental properties at the fundamental level. Third, I argue that these two points - the generalizability of the supervenience argument and type physicalism's incompatibility with fundamental mental properties — combine to undermine type physicalism's identity advantage. The remainder of the paper addresses potential replies to my argument. 


\section{THE GENERALIZABILITY OF THE SUPERVENIENCE ARGUMENT}

A common point made about the supervenience argument is that it generalizes so as to call into question the causal efficacy of all special-science properties (i.e. not just psychological properties but also biological properties, chemical properties, etc.). ${ }^{3}$ This point fits naturally within a layered model of the world, where there is a mereological, or micro-macro, hierarchy of levels that correspond to the different domains of science. On this model, basic physical particles occupy the bottom level and, ascending up the micro-macro hierarchy, those basic particles come together to form atoms, which come together to form molecules, and so on. Moreover, this hierarchy of levels suggests a corresponding hierarchy of properties, where a property belongs to the lowest level at which it is instantiated. Spin and charm, for instance, belong to the bottom level (according to the Standard Model in particle physics), as that is the level at which those properties make their first (and only) appearances. Against this backdrop, the concern arises that the supervenience argument can be adapted to argue that all special science properties, qua higher-level properties, are causally excluded by their lower-level physical bases, thereby draining all causal powers to the fundamental physical level.

Kim (1998: 80-87) denies that his supervenience argument generalizes to such an extent. He emphasizes that higher-level properties and their corresponding lower-level properties will be properties of different objects, since different objects occupy the different levels in the micromacro hierarchy. However, Kim insists, supervenient properties and their base properties belong to the same objects:

In general, supervenient properties and their base properties are instantiated by the same objects and hence are on the same level. This again is a simple consequence of the concept of supervenience: Socrates's goodness supervenes on his honesty, generosity,

\footnotetext{
${ }^{3}$ See, for example, Noordhof 1999, Bontly 2002, and Block 2003.
} 
courage, and wisdom, and it is the same person, Socrates, who instantiates both these subvenient virtues and the supervenient goodness. (Kim 1998: 86).

So, higher-level properties do not supervene on their corresponding lower-level properties, as they are not instantiated by the same objects. Since Kim's supervenience argument relies on the supervenience relation, he concludes that the argument "does not have the effect of emptying macrolevels of casual powers and rendering familiar macro-objects and their properties causally impotent" (Kim 1998: 86).

We should distinguish, then, between two varieties of generalizability for the supervenience argument:

Inter-level generalization: The supervenience argument can be adapted to argue that, for any macro object, its macro properties are causally excluded by micro-physical properties of its proper parts, thereby draining all causal powers to the micro properties of fundamental physical particles.

Intra-level generalization: The supervenience argument can be adapted to argue that, for any macro object, its supervenient properties are causally excluded by subvenient physical properties of the macro object itself, rather than by any micro properties of its proper parts.

Kim, we have just observed, denies inter-level generalization because higher-level properties do not supervene on lower-level properties. But consider the following inter-level relation:

Inter-level dependence: Necessarily, for any higher-level property, $\mathrm{H}$, if $\mathrm{H}$ is instantiated at time $t$, there exists a lower-level physical property (or complex of such properties and relations), $\mathrm{L}$, such that $\mathrm{L}$ is instantiated at $\mathrm{t}$, and necessarily any time at which $\mathrm{L}$ is instantiated $\mathrm{H}$ is instantiated as well.

This relation differs from Kim's supervenience relation in that higher-level properties and their lower-level bases are not had by the same objects; it is not a "same-object relation." Nonetheless, inter-level dependence has enough in common with supervenience so as to generalize the causal exclusion concerns of the supervenience argument to all higher-level properties.

The parallel exclusion argument runs thusly: 
(1*) Assume that an instantiation of a higher-level property, $\mathrm{H}$, causes an instantiation of another higher-level property, $\mathrm{H}^{*}$.

$\left(2^{*}\right)$ By inter-level dependence, $\mathrm{H}^{*}$ has a physical base, $\mathrm{L}^{*}$.

(3*) If $\mathrm{H}$ causes $\mathrm{H}^{*}$ and $\mathrm{H}^{*}$ has physical base $\mathrm{L}^{*}$, then $\mathrm{H}$ causes $\mathrm{H}^{*}$ by causing $\mathrm{L}^{*}$.

(4*) Hence, $\mathrm{H}$ causes $\mathrm{L}^{*}$.

$\left(5^{*}\right)$ By inter-level dependence, $\mathrm{H}$ has a physical base, $\mathrm{L}$.

(6*) If $\mathrm{H}$ causes $\mathrm{L}^{*}$ and $\mathrm{H}$ has physical base $\mathrm{L}$, then $\mathrm{L}$ causes $\mathrm{L}^{*}$.

(7*) Hence, L causes L*.

(8*) By higher-level/lower-level property dualism, $\mathrm{H}$ is distinct from $\mathrm{L}$.

(9*) Hence, $\mathrm{L}^{*}$ has two distinct causes, $\mathrm{H}$ and $\mathrm{L}$.

$\left(10^{*}\right)$ But, by the causal exclusion principle (and the assumption that $\mathrm{L}^{*}$ is not causally overdetermined), this result is unacceptable.

Premise $\left(3^{*}\right)$ is no less plausible than premise (3) of Kim's supervenience argument. Kim (2005: 39-40) argues that if the instantiation of $\mathrm{P}^{*}$ necessitates (is sufficient for) the instantiation of $\mathrm{M}^{*}$, then there appears to be a tension in the instantiation of $\mathrm{M}^{*}$ being further accounted for by M's causal contribution, unless $\mathrm{M}$ causes $\mathrm{M}^{*}$ by causing $\mathrm{P}^{*}$. According to inter-level dependence, the instantiation of L* no less necessitates (is just as sufficient for) the instantiation of $\mathrm{H}^{*}$. So, by parity of reasoning, we have $\left(3^{*}\right)$.

Turn now to premise $\left(6^{*}\right)$. Kim (2005: 41) supports (6) of his supervenience argument in the following way: Because the instantiation of $\mathrm{P}$ necessitates (is sufficient for) the instantiation of $\mathrm{M}$, it looks as though $\mathrm{P}$ counts as a cause of $\mathrm{P}^{*}$ just as much as $\mathrm{M}$ does. ${ }^{4}$ Yet, due to interlevel dependence, the instantiation of L no less necessitates (is just as sufficient for) the instantiation of H. Thus, reasons paralleling Kim's support for (6) are available in support of $\left(6^{*}\right)$.

\footnotetext{
${ }^{4}$ It is worth noting that Kim (2005: 41-45) offers two different completions of his supervenience argument, one of which does not require (6). Rather than using mind-body supervenience to introduce a physical cause of $\mathrm{P} *$, the alternative is to employ causal closure of the physical domain. Starting from step (4), the alternative completion runs as follows:

(4) Hence, M causes $\mathrm{P}^{*}$.

(5') By causal closure of the physical domain, $\mathrm{P}^{*}$ has a physical cause, $\mathrm{P}$.

(6') By mental/physical property dualism, $\mathrm{M}$ is distinct from $\mathrm{P}$.

(7') Hence, $\mathrm{P}^{*}$ has two distinct causes, $\mathrm{M}$ and $\mathrm{P}$.

(8') But, by the causal exclusion principle (and the assumption that $\mathrm{P} *$ is not causally overdetermined), this result is unacceptable.
} 
Kim suggests that taking supervenience to be a same-object relation is important for generating the causal exclusion problems of the supervenience argument. But as we have just seen, Kim's critical steps (3) and (6) in no way employ that aspect of supervenience. One might wonder, though, if the application of the causal exclusion principle in (10) requires $\mathrm{M}$ and $\mathrm{P}$ to be instantiated by the same object. There is no reason, however, to think that this is the case. Thomas Bontly makes the point nicely:

Plainly, it [the causal exclusion principle] does not say that a sufficient cause excludes other causes if but only if they involve properties of the same object, nor does it say that a sufficient cause excludes others if but only if the others supervene in the usual, intralevel manner. We could of course introduce such a restriction, but on what grounds? Ordinarily, when we try to assign causal responsibility for some event, the competing causal explanations do involve properties of different objects. Did the nicotine in his cigarettes cause the cancer, or was it the asbestos in the air? Was the accident caused by the driver's intoxication, or by the icy road conditions? The fact that the properties being intoxicated and being icy are instantiated by different objects in no way lessens the appearance of competition between them. (Bontly 2002: 85)

As made evident with the examples cited by Bontly, concerns of causal exclusion in no way rely on the relevant properties belonging to the same object. Thus, the fact that $\mathrm{M}$ and $\mathrm{P}$ belong to the same object is irrelevant to their being subjected to the causal exclusion principle. But what is relevant is that $\mathrm{M}$ and $\mathrm{P}$ occur at the same time, for the causal exclusion principle does say that a sufficient cause excludes another only if they occur at the same time. It is important for Kim's argument, then, that supervenience is a synchronic relation. ${ }^{5}$ Notice that inter-level dependence is also a synchronic relation. Hence, wielding the causal exclusion principle in $\left(10^{*}\right)$ is no less plausible than Kim's original use of it in (10).

In light of these considerations, it should be evident that taking supervenience to be a same-object relation is irrelevant to generating the causal exclusion problems of the

\footnotetext{
${ }^{5}$ On Kim's alternative completion (see fn. 4), causal closure of the physical domain ensures that M and P occur at the same time.
} 
supervenience argument. The supervenience relation pulls its weight due to being a synchronic necessitation relation. And since inter-level dependence is no less a synchronic necessitation relation, it would extend the supervenience argument's concerns about causal exclusion to all higher-level properties.

Furthermore, any robust version of physicalism appears committed to inter-level dependence. ${ }^{6}$ To see why, consider what Kim (1998: 84) calls "a micro-based property":

$P$ is a micro-based property just in case $P$ is the property of being completely decomposable into nonoverlapping proper parts, $a_{1}, a_{2}, \ldots, a_{n}$, such that $P_{1}\left(a_{1}\right), P_{2}\left(a_{2}\right)$, . $\ldots, P_{n}\left(a_{n}\right)$, and $R\left(a_{1}, \ldots, a_{n}\right)$.

Kim provides the following example:

Being a water molecule therefore is a micro-based property in this sense: it is the property of having two hydrogen atoms and one oxygen atom in a such-and-such bonding relationship. A micro-based property therefore is constituted by micro-constituents - that is, by the micro-parts of the object that has it and the properties and relations characterizing these parts. But we should be clear that such properties are macroproperties, not microproperties. (Kim 1998: 84).

So, a micro-based property is a (higher-level) property that an object possesses in virtue of having certain parts with certain properties and relations (these parts, properties and relations all being lower-level). Inter-level dependence holds, then, if all higher-level properties are micro-physical-based properties, i.e. micro-based properties for which the corresponding lowerlevel constituents are all physical. After all, for any micro-physical-based property plugged in for $\mathrm{H}$, the lower-level properties and relations in virtue of which it is instantiated will satisfy the conditions placed on L. Given this, even if all higher-level properties only supervene on microphysical-based properties, inter-level dependence still holds: for any higher-level property, $\mathrm{H}$,

\footnotetext{
${ }^{6}$ Notice that inter-level dependence does not commit the physicalist to there being any instances of higher-level properties. Just like mind-body supervenience, inter-level dependence is a conditional thesis in that it says what must follow if a property of the relevant sort is instantiated. Furthermore, should one be an eliminativist concerning higher-level properties, then the inability to have higher-level properties that are causally efficacious follows immediately, making the appeal to inter-level generalization unnecessary.
} 
there will be a subvenient micro-physical-based property with a lower-level physical base, L, which serves as a lower-level physical base for $\mathrm{H}$ as well. What is more, it seems that any robust version of physicalism acknowledging higher-level properties would require that they are all either identical with or supervene on micro-physical-based properties. Kim (2005: 59) himself suggests this when he offers macro-micro supervenience as a "plausible physicalist principle."7 Thus, physicalism seems committed to inter-level dependence, which, as we have observed, is the gateway to inter-level generalization. ${ }^{8}$

With inter-level generalization looking plausible, we are halfway to undermining type physicalism's identity advantage. The remaining ingredient is the type physicalist's inability to countenance a mental property at the fundamental level.

\section{TYPE PHYSICALISM'S INCOMPATIBILITY WITH FUNDAMENTAL MENTAL PROPERTIES}

While physicalism is apparently compatible with macro objects, such as brains, having mental properties, I take it that physicalism is not compatible with micro objects at the fundamental level, such as electrons (or whatever the correct theory of physics posits as the elementary particles), having mental properties. According to physicalism, the world is fundamentally physical in a robust sense, which seems to require that the physical have ontological priority over the mental. But if a mental property is just as basic in the hierarchy of

\footnotetext{
${ }^{7}$ Note as well that, as Bontly points out, "it appears that macroproperties which do not supervene on micro-based properties could not be causally efficacious without violating the causal closure of the physical" (Bontly 2002: fn. 9). Any such higher-level properties would, Bontly warns, thus find their causal potency denied by the supervenience argument.

${ }^{8}$ This defense of inter-level generalization leans heavily on Noordhof 1999 and Bontly 2002. For further discussion of inter-level generalization see those works, as well as Kim's (1999) response to Noordhof, which is addressed by Bontly (2002: fn. 12).
} 
levels as any given physical property, then the world is apparently not fundamentally physical in the sense required by physicalism.

Nor would it help to suppose that the mental property at the fundamental level were identical with a physical property. While this would allow for all of the fundamental properties to remain physical, it would nonetheless give mentality equal positioning among the physical properties at the fundamental level. And, again, physicalism appears committed to the physical ultimately having ontological priority over the mental. Even type physicalism, then, is incompatible with fundamental mental properties. ${ }^{9}$

\section{A DILEMMA FOR TYPE PHYSICALISM'S IDENTITY ADVANTAGE}

We are now in a position to expose a problem for type physicalism's identity advantage.

Due to inter-level generalization, the only properties that clearly avoid concerns of causal exclusion are fundamental physical properties, i.e. properties of micro-physical objects at the fundamental level. So, in order for type physicalism to preserve its identity advantage over nonreductive physicalism, type physicalism must identify mental properties with fundamental physical properties. But this cannot be done due to type physicalism's inability to countenance fundamental mental properties.

The problem can be summed up in the form of a dilemma. On the one hand, if type physicalism does not posit fundamental mental properties, then it loses its identity advantage. On the other hand, if type physicalism does posit fundamental mental properties, then it no longer counts as a version of physicalism. Therefore, even if mental-physical property identities were

\footnotetext{
${ }^{9}$ This claim that type physicalism is incompatible with fundamental mental properties will be revisited below (in section VII. AVOIDING THE SECOND HORN: SECOND ATTEMPT), where certain considerations will prompt us to refine the claim slightly.
} 
available upon request, type physicalism would not offer the physicalist an easy way out of the exclusion problems raised by Kim's supervenience argument.

The remainder of the paper will be devoted to addressing potential responses to this argument, beginning with attempts to avoid the first horn of the dilemma.

\section{AVOIDING THE FIRST HORN: FIRST ATTEMPT}

The generalizability of the supervenience argument is often taken to show that something is wrong with the argument. ${ }^{10}$ According to this line of reasoning, it is clear that many special science properties (e.g., properties distinctive of biology and neurology) are causally efficacious and, therefore, any argument entailing otherwise (such as the supervenience argument) must be flawed. One might, in the following way, attempt to adapt this point in order to regain the type physicalist's identity advantage: Identifying mental properties with biological or neurological properties is sufficient for securing the causal efficacy of the mental, for it is clear that biological and neurological properties are causally efficacious. Thus, the type physicalist need not reduce mental properties below the biological or neurological levels in order to avoid the causal exclusion of the mental, for there is obviously biological and neurological causation. And if the supervenience argument does generalize so as to threaten the causal efficacy of such special science properties - if there is inter-level generalization - then that only goes to show the absurdity of the supervenience argument.

Such a reply, however, is unsuccessful. The supervenience argument attempts to show how certain metaphysical assumptions (i.e. mind-body supervenience, causal closure of the physical domain, mental/physical property dualism, and the causal exclusion principle) are

\footnotetext{
${ }^{10}$ See, for example, Baker 1993 and Burge 1993.
} 
incompatible with the causal efficacy of mental properties. And no one maintaining those metaphysical assumptions can avoid addressing this concern by simply falling back on one's conviction that mental properties are in fact causally efficacious. As Kim aptly labels it, this is the "unavoidability of metaphysics." $" 11$ Thus, contrary to undermining the supervenience argument, its generalizability amplifies the demand to take a closer look at where causation is able to take place on one's metaphysical view.

Moreover, suppose (for the sake of argument) that the generalizability of the supervenience argument enabled the type physicalist to disregard such concerns of causal exclusion. A parallel move can be made by the non-reductive physicalist in order to avoid the supervenience argument. Type physicalism, then, still loses its identity advantage. This failure to regain its identity advantage results from the type physicalist relying ultimately not on mental/physical identities in order to avoid the causal exclusion of the mental but, rather, on a line of reasoning that is equally available to (and already employed by) the non-reductive physicalist. ${ }^{12}$

\section{AVOIDING THE FIRST HORN: SECOND ATTEMPT}

Ned Block (2003) suggests that, from the perspective of contemporary physical theory, it is an open question whether or not there is a fundamental level. Objects might be infinitely divisible, so that, for any level of objects and their corresponding properties, there will be a lower level of even smaller objects with their corresponding properties. If this is the case, then

\footnotetext{
${ }^{11}$ Kim offers this line of reply to Baker (1993) and Burge (1993) in his section titled "Unavoidability of Metaphysics: The Exclusion Problem" (Kim 1998: 60-67).

${ }^{12}$ Note, then, that the present paper's challenge to type physicalism's identity advantage does not require the supervenience argument to be sound. The claim is that mental-physical property identities would not provide the physicalist with an easy answer to such concerns of causal exclusion, which is perfectly compatible with there being other solutions available.
} 
(one might argue) the type physicalist is at no risk of identifying a mental property with a fundamental physical property, for there is no fundamental level. So, whenever (due to interlevel generalization) a mental property is shown to be causally excluded by a lower-level physical property, it is consistent with type physicalism that there be some other mental property that is identical with that lower-level physical property. ${ }^{13}$ And such mental-physical identities holding "all the way down" would prevent inter-level generalization from showing that mental causation is incompatible with type physicalism; wherever the causal powers of higher-level mental properties drain to, there will be a lower-level mental property with just as much claim to those causal powers as any given physical property. Thus, if there is no fundamental level, type physicalism need not identify mental properties with fundamental physical properties in order to preserve its identity advantage.

To this, three lines of reply are available. First, even if the hypothesis that there is no bottom level is seen as a real possibility (as opposed to what Block calls a "mere philosopher's possibility"), that is not enough for the above account to secure type physicalism's identity advantage in avoiding the causal exclusion of the mental. That advantage is supposed to be based on more than an open question or real possibility; it is supposed to be an obvious and wellestablished advantage. Second, it is unclear that endless mental-physical identities would be consistent with physicalism. If mental-physical property identities extend "all the way down," then the mental would be on par with any given physical property in the hierarchy of levels, thereby undermining physicalism's commitment to the ontological priority of the physical over

\footnotetext{
${ }^{13}$ One might wonder why a second mental property is introduced. Why not simply identify the higher-level mental property itself with the lower-level physical property threatening its causal efficacy? Because, as Bontly points out, "if two properties are one and the same, then surely every object which instantiates one must also instantiate the other" (Bontly 2002: 88). Therefore, the Indiscernibility of Identicals prevents one from identifying a higher-level property with its corresponding lower-level property, since the two properties will belong to different objects in the micro-macro hierarchy. Note as well, then, that this point prevents one from denying higher-level/lower-level property dualism, featured in premise ( $8^{*}$ ) of our parallel exclusion argument.
} 
the mental. ${ }^{14}$ Third, even if the type physicalist were allowed mental-physical property identities "all the way down," it is far from clear that such identities would help in securing mental causation. In the context of the generalizability of the supervenience argument, the absence of a fundamental level is typically taken to result in causal powers draining away, so that there is no causation at all! ${ }^{15}$ Therefore, the lack of a fundamental level would only magnify type physicalism's lack of an identity advantage, for inter-level generalization would then suggest that there is not even physical causation.

So much for attempts to avoid the first horn of the dilemma facing type physicalism's identity advantage. We will now turn to addressing attempts to avoid the second horn of the dilemma. That horn, recall, claims that if type physicalism posits fundamental mental properties, then it no longer counts as a version of physicalism.

\section{AVOIDING THE SECOND HORN: FIRST ATTEMPT}

According to a supervenience formulation of physicalism, all properties, including mental properties, supervene on physical properties. Now, take the formulation of mind-body supervenience featured in Kim's supervenience argument. This supervenience thesis is compatible with every mental property being identical with a fundamental physical property. Indeed, such mental-physical identities would entail mind-body supervenience. Therefore, with a supervenience formulation of physicalism, one might argue that type physicalism can countenance mental-physical property identities at the fundamental level.

\footnotetext{
${ }^{14}$ Rosen (2010: 111) observes that taking mental (intentional) facts to be fundamental (brute facts) is incompatible with a naturalistic metaphysics. And, in line with our present point, he indicates that it is no less incompatible with naturalism to posit an infinitely descending chain of intentional facts obtaining in virtue of other intentional facts.

${ }^{15}$ See, for example, Block 2003.
} 
Notice, however, that the formulation of mind-body supervenience given with Kim's supervenience argument is not sufficient for capturing physicalism. As it stands, the formulation specifies merely a covariance between mental and physical properties. And as Kim rightly points out, "Mind-body supervenience as a bare claim about how mental and physical properties covary will be accepted by the double-aspect theorist, the neutral monist, the emergentist, and the epiphenomenalist; it can be accepted even by the substance dualist" (Kim 2005: 34). ${ }^{16}$ The problem, then, is that the formulation of mind-body supervenience at hand is compatible with paradigmatically non-physicalist positions. ${ }^{17}$

One might, of course, supplement the mental-physical covariance of mind-body supervenience in order to help specify a sufficiently physicalist picture. This is the route Kim himself takes. According to Kim, there must also be an ontological or existential relation of dependence, where that sense of dependence "justifies saying that a mental property is instantiated in a given organism at a time because, or in virtue of the fact that, one of its physical 'base' properties is instantiated by the organism at that time" (Kim 2005: 34). Furthermore, Kim suggests that this ontological dependence must be asymmetric:

The relation of dependence, or determination, is asymmetric: if $x$ depends on, or is determined by $y$, it cannot be that $y$ in turn depends on or is determined by $x$. What does the determining must be taken to be, in some sense, ontologically prior to, or more basic than, what gets determined by it.... In fact common expressions like "supervenience base" and "base property" all but explicitly suggest asymmetric dependence. (Kim 1998: 11)

\footnotetext{
${ }^{16}$ It is worth pointing out that Kim's claim here about substance dualism is incompatible with his insistence on supervenience being a same-object relation. According to substance dualism, mental properties and physical properties are not had by the same objects. Thanks to an anonymous referee for the Journal of Philosophical Research for highlighting this conflict.

${ }^{17}$ Observe that the popular supervenience slogan of no mental difference without a physical difference is similarly insufficient for capturing physicalism, for it specifies only a mental-physical covariance that is compatible with nonphysicalist views like parallelism and double-aspect theory.
} 
Such an asymmetric ontological dependence makes mind-body supervenience much more effective in securing a fundamentally physical world in the sense required by physicalism. The more robust this asymmetric grounding of the mental in the physical, the stronger the ability of mind-body supervenience to rule out non-physicalist views like parallelism and double-aspect theory.

But while an asymmetric ontological dependence in mind-body supervenience brings one closer to physicalism, it pushes one away from countenancing a mental-physical property identity at the fundamental level. If $\mathrm{X}$ is identical with $\mathrm{Y}$, then $\mathrm{X}$ cannot have an asymmetric ontological dependence on $\mathrm{Y}$. Claiming that $\mathrm{X}$ has an asymmetric ontological dependence on $\mathrm{Y}$, when $\mathrm{X}$ is identical with $\mathrm{Y}$, would have the absurd consequence of $\mathrm{X}$ both depending on itself and, at the same time, not depending on itself. Therefore, the supervenience formulation of physicalism still fails to show that physicalism is compatible with the identification of mental properties with fundamental physical properties. ${ }^{18}$

In response, one might simply adjust the supervenience formulation of physicalism to the following: All properties, except those properties that are identical with physical properties, supervene on physical properties with asymmetric ontological dependence. This formulation of physicalism is clearly compatible with a mental property being identical with a fundamental physical property. Yet notice that it is also compatible with every fundamental physical property

\footnotetext{
${ }^{18}$ Post (1999) also recognizes that the identity of one property with another prevents there being an asymmetric relation of determination between the two properties. He argues that mind-body supervenience should not be understood as requiring an asymmetric determination relation, because all physicalists require at least some higherlevel properties to be identical with physical properties. However, the examples Post employs (e.g. all physicalists requiring that being red is identical with having a certain triplet of electromagnetic reflectance efficiencies) concern physical properties that are not fundamental properties in the micro-macro hierarchy (i.e. the relevant physical properties do not belong to the elementary particles at the fundamental level). Thus, there remains room for nonreductive physicalists to insist that all higher-level properties supervene on fundamental physical properties with asymmetric ontological dependence. (This would, though, involve a notion of supervenience that allows for supervenient properties and their base properties to be had by different objects.)
} 
being identical with a mental property. Plainly, such a panpsychism at the fundamental level is not compatible with the world being fundamentally physical in the sense required by physicalism, for the world would be equally fundamentally mental! ${ }^{19}$ Nor is it sufficient for regaining a physicalist picture that one further modify the supervenience formulation of physicalism to include the condition that not all fundamental physical properties are identical with mental properties. Suppose that every fundamental physical property except one were identical with a mental property. That single, non-mental property would surely fail to make the fundamental level physicalistically acceptable. And I do not see any non-arbitrary line physicalists could draw, below one hundred percent, for the required, minimal percentage of fundamental physical properties that are non-mental properties.

\section{AVOIDING THE SECOND HORN: SECOND ATTEMPT}

One might argue that there is room to countenance a mental property at the fundamental level without undermining the ontological priority of the physical. There is no principled reason why micro objects at the fundamental level cannot have supervenient properties. And if a mental property at the fundamental level supervenes on a physical property in an ontologically robust and asymmetric fashion, then the physical can ultimately retain ontological priority over the mental. Type physicalism may, therefore, identify a mental property with a fundamental physical property, so long as the fundamental physical property supervenes (in an ontologically robust and asymmetric fashion) on a fundamental physical property that is not mental.

\footnotetext{
${ }^{19}$ Strawson (2006) does take physicalism to be compatible with panpsychism. However, Strawson is clear that he is working with a notion of physicalism other than that which is typically found in contemporary debates among philosophers, allowing that "anyone who prefers to call my position 'realistic monism' instead of 'real physicalism' should feel free to do so" (Strawson 2006: 8-9).
} 
Of course, there is the concern that we are not micro physical entities at the fundamental level (I, for instance, am not an electron) and, so, saving mental causation at that level is not securing the sort of mental causation we really care about, namely, our own $!^{20}$ But even putting aside this concern, the above line of reply still fails to regain type physicalism's identity advantage. To see why, we should distinguish between two sorts of fundamentality. On the one hand, there is fundamentality in the hierarchy of levels, which involves being at the fundamental level in the micro-macro hierarchy. On the other hand, there is fundamentality in the hierarchy of supervenience, which involves being a property that does not supervene on any other property. The above reply shows how the type physicalist may identify a mental property with a physical property that is fundamental in the hierarchy of levels but not also in the hierarchy of supervenience. Therefore, while the causal efficacy of such a mental property is safe from interlevel generalization, it is not safe from intra-level generalization. ${ }^{21}$

In light of this, we can refine the dilemma for type physicalism's identity advantage. On the one hand, if type physicalism does not posit mental properties that are fundamental (in both the hierarchy of levels and supervenience), then it loses its identity advantage (due to inter-level and/or intra-level generalization). On the other hand, if type physicalism does posit fundamental mental properties (in both the hierarchy of levels and supervenience), then it no longer counts as a version of physicalism.

\footnotetext{
${ }^{20}$ Furthermore, as pointed out by an anonymous referee for the Journal of Philosophical Research, this objection does not apply generally to views that preserve mental causation for only fundamental properties, since they could belong to fundamental mental particulars (e.g., Cartesian egos) that are better candidates for being the sort of thing we are.

${ }^{21}$ Although the initial formulation of intra-level generalization focused on macro objects, that was merely to help contrast intra-level generalization with inter-level generalization. It should be clear that intra-level generalization is just as plausible when formulated with respect to any object, macro or micro:

Intra-level generalization: The supervenience argument can be adapted to argue that, for any object at any level in the micro-macro hierarchy, its supervenient properties are causally excluded by its subvenient physical properties.
} 


\section{CONCLUSION}

Type physicalism, with its identification of mental properties with physical properties, initially appears to have an unquestionable advantage over non-reductive physicalism in avoiding the causal exclusion problems raised by the supervenience argument. However, we have seen this identity advantage undermined by the generalizability of the supervenience argument and type physicalism's inability to countenance fundamental mental properties. Type physicalists must wrestle with the causal exclusion of the mental to the same extent as nonreductive physicalists - the appeal to mental-physical identities provides no refuge. ${ }^{22}$

\section{BIBLIOGRAPHY}

Baker, Lynne Rudder. 1993. "Metaphysics and Mental Causation.” In John Heil \& Alfred Mele (eds.), Mental Causation. Oxford: Clarendon Press, 75-95.

Block, Ned. 2003. “Do Causal Powers Drain Away?” Philosophy and Phenomenological Research 67: 133-150.

Bontly, Thomas. 2002. “The Supervenience Argument Generalizes.” Philosophical Studies 109: 75-96.

Burge, Tyler. 1993. "Mind-Body Causation and Explanatory Practice.” In John Heil \& Alfred Mele (eds.), Mental Causation. Oxford: Clarendon Press, 97-120.

Kim, Jaegwon. 1998. Mind in a Physical World. Cambridge, MA: MIT Press. 1999. "Supervenient Properties and Micro-based Properties: A Reply to Noordhof." Proceedings of the Aristotelian Society 99: 115-118.

\footnotetext{
${ }^{22}$ For their helpful feedback on drafts of this paper, I would like to thank Paul Audi, John Heil, Adam Podlaskowski, Justin Tiehen, and those who attended my presentation at the University of Toronto. I am also grateful to the National Endowment for the Humanities for financial support.
} 
— 2005. Physicalism or Something Near Enough. Princeton: Princeton University Press.

Noordhof, Paul. 1999. "Micro-Based Properties and the Supervenience Argument: A Response to Kim." Proceedings of the Aristotelian Society 99: 109-114.

Post, John. 1999. “Is Supervenience Asymmetric?” In L. C. Pereira \& M. Wrigley (eds.), Logic, Language, and Knowledge: Festshcrift in Honor of Oswaldo Chateaubriand. Manuscrito, XXII, 305-344.

Rosen, Gideon. 2010. "Metaphysical Dependence: Grounding and Reduction.” In Bob Hale \& Aviv Hoffmann (eds.), Modality: Metaphysics, Logic, and Epistemology. Oxford: Oxford University Press, 109-135.

Strawson, Galen. 2006. "Realistic Monism: Why Physicalism Entails Panpsychism," Journal of Consciousness Studies 13: 3-31. 